\title{
Pattern and frequencies of patients with abdominal trauma admitted to ICU of tertiary care center (southern region, Saudi Arabia)
}

\author{
Ali Albshabshe, Fahad Abdullah Saeed Al Jarad, Jubran Safar Mater Al Shahrani , Salah \\ Saeed al Jathnan Al Qahtani, Saeed Mohammed Saeed Alghamdi, Ali Ahmad Saeed Alsaleem, \\ Mohammed Saeed Abdullah Alqahtani
}

\author{
Department of Internal Medicine, College of Medicine, King Khalid University (KKU) \\ Correspondence Author: Ali Albshabshe, NUMBER: 0504740409, Email albshabshe@ YAHOO.com
}

\begin{abstract}
Background: Traumatic injuries are a significant threat to public health worldwide, nowadays trauma has become the greatest reason of death particularly in the under developing countries. As per the Korean emergency medicine report, the ratio of trauma patients increased from $1.87 \%$ in 2007 to $2.71 \%$ in 2011 . It remains a major public health problem in every country.

Methods: In a cross sectional retrospective study design, we reviewed randomly selected 200 poly trauma patient's files during the period from June 2016 till May 2017.

Results: A total of 200 patient's data were randomly retrieved, 162 (81\%) were between age of 18-45 years of, $126(63 \%)$ less than 30 years.184 (92\%) were males. $168(84 \%)$ were motor vehicle accidents and the rest between gunshot, stab wounds and falls.

Conclusion:Abdominal trauma is common among young poly trauma patients and the commonest cause is the motor vehicle accidents. We need an urgent and effective intervention at regional and national level to drop and stop car accidents.
\end{abstract}

Keywords: Trauma, accident, mortality

\section{Introduction:}

In Saudi Arabia (SA), injuries are the second leading cause of death; however, little is known about their frequencies and outcomes. In southern region of Saudi Arabia nearly every day there are an ICU admission related to trauma especially motor vehicle accident. During these days trauma became the greatest reason of death particularly in the under developing countries, As per the Korean emergency medicine report, the ratio of trauma patients increased from $1.87 \%$ in 2007 to $2.71 \%$ in $2011^{1}$.It remains a major public health problem in every country. An approximate estimation tells us that five million peoples died per year due to the trauma ${ }^{2}$. WHO published that near or in 2020 , possibly trauma will be the highest or second highest reason for disabilities and wastage of the precious time of the life. A higher prevalence of injury \& death was observed due to the $\mathrm{BTI}^{3}$. The prevalence of BTI is increasing day by day in the Gulf region. The frequency of abdominal trauma in patients is lying between $7-10 \%{ }^{4}$. Italian study stated that out of 844 patients 79 of them (9.3\%) have abdominal trauma ${ }^{5}$. Communal causes of blunt abdominal trauma are, falls from height, traffic accidents, assaults and accidents in industries, study stated that the abdomen is almost the $3^{\text {rd }}$ commonest injured organ ${ }^{6}$.

In previously published study we noticed that road traffic accidents created $83.6 \%$ of blunt abdominal trauma. Death rates increased in patients with blunt abdominal trauma as compared with other injuries ${ }^{7}$.

The study is designed to fulfill the gap in data regarding the outcome and prognosis of abdominal trauma in patients admitted to intensive care unit of tertiary care center in southern region Saudi Arabia.

\section{Methods:}

A cross sectional retrospective study of patients admitted to ICU of a tertiary care critical care unit in southern region with abdominal trauma in which a chart review performed for all study subjects. This review was from June 2016 till May 2017.

The main outcome was to determine the pattern of abdominal trauma in patients admitted to the critical care department during the study period. 


\section{Inclusion criteria:}

Adult patients who were admitted to the critical care department during the study period were 12 years and older.

\section{Exclusion criteria:}

Pediatric age group trauma (less than 12 years)

\section{Data gathering:}

Data was obtained from the constructed data collection sheet (information transferred from the patient file to the data sheet) and entered in the SPSS software version 20 for analysis.

\section{Statistical analyses:}

Descriptive (mean, s.d, frequencies and percentages) were calculated. Graphs were generated to represent the data.

\section{Software:}

SPSS ver. 20 was used for analyses

\section{Results:}

A total of 200 patient's data were randomly retrieved, $162(81 \%)$ were between the age of $18-45$ years, $126(63 \%)$ less than 30 years .184 (92\%) were males. 168 (84\%) were motor vehicle accidents and the rest between gunshot, stab wounds and falls .156 (78\%) were mechanically ventilated .115 (58\%) had associated head injuries ranging from mild to severe injuries. $63(30 \%)$ had spinal cord injuries. 66 (33\%) had associated chest injuries .57 (29\%) had limb injuries and 25(13\%) had associated pelvis fractures.

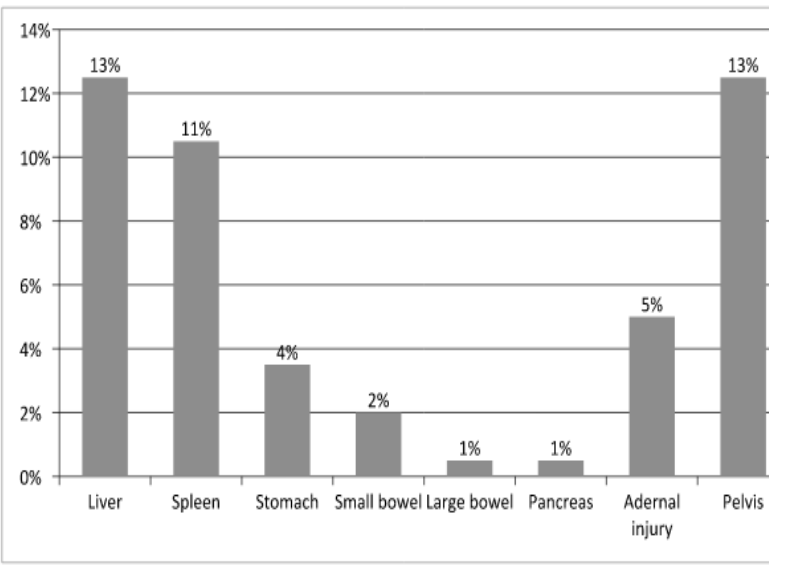

Fig. 1 Distribution of abdominal trauma

Among the abdominal injuries there was 25 patients (13\%) liver trauma which was ranging from grade G1 $1.5 \%, \mathrm{G} 22.5 \%, \mathrm{G} 32.5, \mathrm{G} 4$ $2.5 \%$ and G5 $2.5 \%$, while there were 21patients (11\%) who had splenic trauma which was ranging from grade G1 6 patients, G2 8 patients, G3 5 patients and G4 2 patients
.7 patients $(3.5 \%)$ had stomach injury, 4 (2\%) patients had small bowel injuries. One patient $(0.5 \%)$ had large bowel injury which was mainly rectal injury, one patient $(0.5 \%)$ had pancreatic trauma which was pancreatic head. lastly there were 10 patients $(5 \%)$ who had adrenal gland injuries (7in the right adrenal gland, 2 in the left and one patient had bilateral adrenal gland injuries). The outcome 160 $(80 \%)$ survived to discharged.

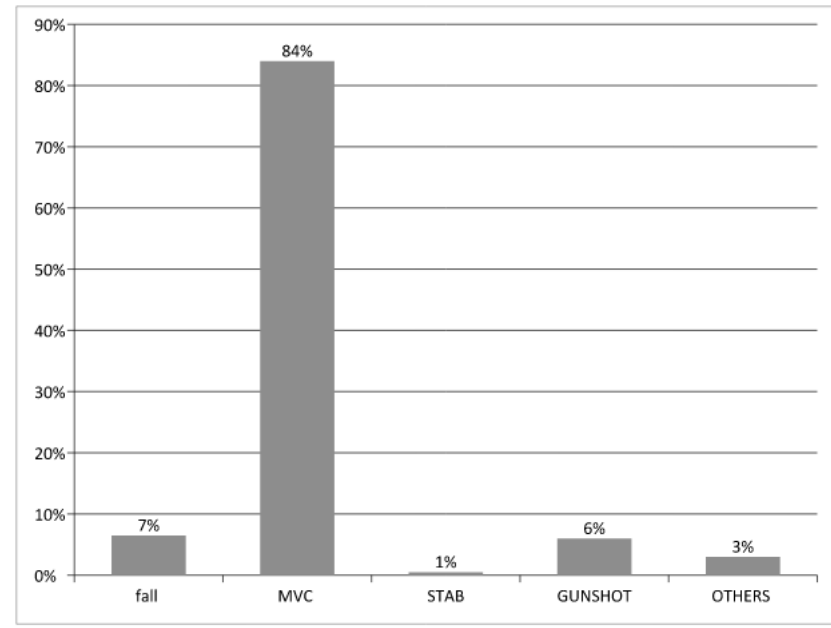

Fig. 2 Mechanism of injury

\section{Discussion:}

In this current era, the number of cars per households rapidly increases in Saudi Arabia which ultimate's increases the number of accidents and injuries which leads to stress for the patients and suffered families ${ }^{8}$.

One study stated that from 3796 patients $(32.1 \%)$ suffered from head injury, car/bike accidents was the topmost cause (34.2\%) for those injuries 9 . Another study from Egypt stated that almost 3,675 patients died in the year 2015 from avoidable injuries ${ }^{10}$. In line with our study one study from Pakistan described that age group lies between 20-45 suffering more from the trauma diseases/injuries ${ }^{11}$. These findings were also confirmed by some other studies i.e. study in the USA by Ball and Croley, in India by Gupta et al. and in the UK by Saad and Alpar ${ }^{12-14}$. In our study, $84 \%$ have MVA injury, the reason behind this is the lack of public awareness regarding traffic rules and careless attitudes. Road traffic accidents are the most common factors which lead to blunt abdominal trauma, as identified by different international studies i.e. $48 \%$ in the UK, $67 \%$ in France ${ }^{15}$. In our study, the next major cause 
was fall from height $7 \%$. In this study, the most common organ to be injured was the liver (13\%) liver injuries were also reported by Hussain et al. (add no of ref) In our study 11 $\%$ patients had spleen injuries. Our study reported 20\% mortality; which is in line with Pakistan $(13.3 \%)^{16 .}$

\section{Conclusion:}

Abdominal trauma is common among young poly trauma patients and the commonest cause is the motor vehicle accidents. We need an urgent and effective intervention at regional and national level to drop and stop car accidents.

\section{References:}

1. Byun CS, Park IH, Oh JH, Bae KS, Lee KH, Lee E(2015): Epidemiology of Trauma Patients and Analysis of 268 Mortality Cases: Trends of a Single Center in Korea. Yonsei Medical Journal,56(1):220-226.

2. Thurman DJ, Alverson C, Dunn KA, Guerrero J, Sniezek JE(1999): Traumatic brain injury in the United States: A public health perspective. J Head Trauma Rehabil.,14: 602-615.

3. Hyder A, A Wunderlich C ,Puvanachandra P, Gururaj G , Kobusingye $O$ (2007): The impact of traumatic brain injuries: A global perspective. Neuro Rehabilitation, 22: 341-53.

4. Asim M, El-Menyar A, Al-Thani H, Abdelrahman H, Zarour A, Latifi $\mathbf{R}(2014)$ : Blunt traumatic injury in the Arab Middle Eastern populations.: Journal of Emergencies, Trauma and Shock,7(2):88-96.

5. Costa G, Tierno SM, Tomassini F, Venturini L, Frezza B, Cancrini G, Stella F (2014):. The epidemiology and clinical evaluation of abdominal trauma. : An analysis of a multidisciplinary trauma registry. Ann Ital Chir. , 81:95-102.

6. Arumugam S, Ammar A ,El-Menyar H,Hassan A (2015): Frequency, Causes and Pattern of Abdominal Trauma: A 4Year Descriptive Analysis. Journal of Emergencies, Trauma, and Shock, 8 (4): 193-198.
7. Sude N, Suryawanshi P (2014): Blunt Abdominal Trauma in RTA Patient -A State of Industrial Anarchy. : International Journal of Science and Research. IJSR., 3 :806-812.

8. Sonbol AM, Almulla AA, Hetaimish BM, Taha WS, Mohmmedthani TS, Alfraidi TA, Alrashidi YA (2018) : Prevalence of femoral shaft fractures and associated injuries among adults after road traffic accidents in a Saudi Arabian trauma center. J Musculoskelet Surg Res., http://www.journalmsr.com/text.asp

9. Sultan A,Mohammed Z,Manal A,Hala M, Manal A,Khalid A,Salem A, Amro A (2013) : Epidemiology of traumatic head injury in children and adolescents in a major trauma center in Saudi Arabia: implications for injury prevention. Ann Saudi Med., 33(1): 52-56.

10. Nourhan $M$, Tue A(2017): Trauma care in Egypt: how to efficiently meet patients' needs? : Egypt today, 18: 217.

11. Aziz A, Bota R, Ahmed M (2014) : Frequency and Pattern of Intra Abdominal Injuries in Patients with Blunt Abdominal Trauma. : J Trauma Treat ., 3: 196.

12. Khan S, Alpar EK (1997) : Abdominal solid organ injuries in multi trauma patients, incidence and etiology: a retrospective analysis of 111 cases. : $J$ Surg. , 14: 44-47.

13. Ball SK, Croley GG (1996) : Blunt abdominal trauma. A review of 637 patients. : J Miss State Med Assoc. , 37: 465-468.

14. Gupta S, Talwar S, Sharma RK, Gupta P, Goyal A, Prasad P (1996) : Blunt trauma abdomen: a study of 63 cases. : Indian J Med Sci ., 50: 272-276.

15. Kunin N, Letoquart JP, La Gamma A, Chaperon J, Mambrini A (1994): Intestinal-mesenteric lesions of closed abdominal traumas. : J Chir (Paris), 131: 129-134.

16. Hassan $S$, Yar M, Khalid $M$ and Imran A (2016) : Mortality Prediction in Patients Admitted in Surgical Intensive Care Unit by Using APACHE IV. : Journal of the College of Physicians and Surgeons Pakistan, 26 (11): 877-880. 